ОАносторонняя внезапная сенсоневральная тугоухость при COVID-19. Кяинические наблюдения и обзор митературы

\author{
С. В. Астащенко ${ }^{1}$, С. М. Мегрелишвили ${ }^{1}$, Я. ^. Щербакова ${ }^{1}$
}

1 Санкт-Петербургский научно-исследовательский институт уха, горла, носа и речи, 190013, Санкт-Петербург, Россия

\title{
Unilateral sudden sensorineural hearing loss in COVID-19. Clinical observations and literature review
}

\author{
S. V. Astashchenko ${ }^{1}$, S. M. Megrelishvili ${ }^{1}$, Ya. L. Shcherbakova ${ }^{1}$ \\ 1 Saint Petersburg Research Institute of Ear, Throat, Nose and Speech, \\ Saint Petersburg, 190013, Russia
}

\begin{abstract}
В конце 2019 г. в Китайской Народной Республике (КНР), г. Ухань, началась вспышка новой коронавирусной инфекции, которая фактически является первой пандемией XXI века. Международный комитет по таксонометрии вирусов классифицировал возбудителя нового заболевания как SARS-CoV-2, a 11 февраля 2020 г. Всемирная организация здравоохранения (ВОЗ) объявила официальное название инфекции - COVID-19. Согласно статистическим данным на август 2021 г. количество зараженных SARS-CoV-2 в мире составляет 216 млн, а число умерших - 4,5 млн человек. COVID-19 может протекать бессимптомно или проявляться различной клинической манифестацией, в том числе неврологической и оториноларингологической. В статье представлено описание 3 клинических случаев одностороннего внезапного ухудшения слуха у пациентов с подтвержденным COVID-19. Диагноз односторонней сенсоневральной тугоухости был установлен с помощью акуметрии, тональной пороговой аудиометрии, акустической импедансометрии и регистрации отоакустической эмиссии. COVID-19 в большинстве случаев характеризуется определенной клинической картиной, однако при бессимптомном и легком течении возможно нетипичное проявление заболевания с развитием внезапной сенсоневральной тугоухости.
\end{abstract}

Ключевые слова: SARS-CoV-2, COVID-19, внезапная сенсоневральная тугоухость, ушной шум, ПЦР.

Для цитирования: Астащенко С. В., Мегрелишвили С. М., Щербакова Я. Л. Односторонняя внезапная сенсоневральная тугоухость при COVID-19. Клинические наблюдения и обзор литературы. Российская оториноларингология. 2021;20(5):75-81. https://doi.org/10.18692/1810-4800-2021-5-75-81

At the end of 2019, an outbreak of a new coronavirus infection began in China, Wuhan, which is the first pandemic of the 21st century. The International Committee on Taxonomy of Viruses has classified the causative agent of the new disease as SARS-CoV-2, and on February 11, 2020, the World Health Organization (WHO) announced the official name of the infection - COVID-19. According to statistics for August 2021, the number of people infected with SARS-CoV-2 in the world is 216 million, and the number of deaths is 4.5 million. COVID-19 can be asymptomatic or manifest with various clinical manifestations, including neurological and otorhinolaryngological. The article describes 3 clinical cases of unilateral sudden hearing impairment in patients with confirmed COVID-19. The diagnosis of unilateral sensorineural hearing loss was established using acumetry, tone threshold audiometry, acoustic impedance measurement, and recording of otoacoustic emissions. In most cases, COVID-19 is characterized by a certain clinical picture, however, with an asymptomatic and mild course, an atypical manifestation of the disease with the development of sudden sensorineural hearing loss is possible. Keywords: SARS-CoV-2, COVID-19, sudden sensorineural hearing loss, tinnitus, PCR.

For citation: Astashchenko S. V., Megrelishvili S. M., Shcherbakova Ya. L. Unilateral sudden sensorineural hearing loss in COVID-19. Clinical observations and literature review. Rossiiskaya otorinolaringologiya. 2021;20(5):75-81. https://doi.org/10.18692/1810-4800-2021-5-75-81 
В декабре 2019 г. в городе Ухань, провинция Хубей, КНР, началась вспышка заболевания неясной этиологии с преимущественным поражением нижних дыхательных путей [1-3]. В дальнейшем этиологический фактор инфекции был идентифицирован как вирусный агент, который является одним из представителей семейства коронавирусов [4].

Коронавирусы (Coronaviridae) - это большое семейство РНК-содержащих оболочечных вирусов, способных инфицировать как животных, так и человека. Заболевания, вызванные данными инфекционными агентами, могут проявляться различной клинической картиной с поражением дыхательной, пищеварительной и нервной систем $[1,2]$.

В настоящее время среди населения циркулируют четыре сезонных коронавируса (HCoV-229E, -OC43, -NL63 и -HKU1), которые, как правило, вызывают поражение верхних дыхательных путей легкой и средней степени тяжести, а также два высокопатогенных коронавируса - SARS-CoV и MERS-CoV. В 2002 г. SARS-CoV впервые стал причиной развития эпидемии атипичной пневмонии TOPC, а в 2014 г. - MERS-CoV эпидемии ближневосточного коронавирусного синдрома $[1,5]$.

Международный комитет по таксонометрии вирусов [The International Committee on Taxonomy of Viruses (ICTV)] классифицировал возбудителя нового инфекционного заболевания как SARS-CoV-2 (Severe Acute Respiratory Syndrome Cronavirus 2). 11 февраля 2020 г. Всемирная организация здравоохранения (ВОЗ) анонсировала официальное название инфекции, вызванной новым коронавирусом, - COVID-19 (Coronavirus Disease 2019) [1, 4, 6, 7].

11 марта 2020 г. ВОЗ объявила пандемию COVID-19 ввиду колоссальной скорости распространения заболевания по всему миру [6]. Согласно официальным статистическим данным университета Джонса Хопкинса (Johns Hopkins University, USA) по состоянию на август 2021 г. в мире количество зараженных SARS-CoV-2 насчитывает 215739 166, а число умерших -4 490820 человек [8]. В Российской Федерации первый случай COVID-19 был зафиксирован в конце января 2020 г. и по состоянию на август 2021 г. количество выявленных случаев составляет 6863541 с долей умерших 180840 человек. Коэффициент летальности [доля лиц с диагностированным заболеванием, умерших в результате этого заболевания (ВО3, 2020)] за весь период пандемии характеризуется непостоянным значением и в настоящее время составляет в мире $2,1 \%$.

Инкубационный период в среднем длится 5 дней (2-7), в 97,5\% случаев первые симптомы заболевания появляются на 11,5 сутки от момента инфицирования [2, 3]. COVID-19 может проте- кать бессимптомно или проявляться различной клинической манифестацией $[2,9]$.

Новая коронавирусная инфекция характеризуется полиорганным поражением, в связи с чем клиническая картина отличается выраженной вариабельностью и может сопровождаться респираторными, кардиологическими, офтальмологическими, дерматологическими, гематологическими симптомами, а также симптомами поражения желудочно-кишечного тракта и нервной системы $[2,9]$.

В большинстве случаев заболевание протекает либо бессимптомно, либо в легкой или среднетяжелой форме и не требует назначения специфической терапии. Тяжелая форма COVID-19 наблюдается у лиц пожилого возраста, а также у пациентов, имеющих иммунодефицитные состояния и сопутствующие хронические заболевания (сердечно-сосудистые заболевания, сахарный диабет, избыточный вес и пр.), и может сопровождаться развитием серьезных осложнений, таких как острый респираторный дистресс-синдром (ОРДС), тромбоэмболия легочной артерии (ТЭЛА), острые нарушения мозгового кровообращения (ОНМК), синдром Гийена - Барре и пр. $[10,11]$.

Основными оториноларингологическими проявлениями, которые на данный момент рассматриваются как одни из патогномоничных признаков COVID-19 [12], особенно в случае бессимптомного течения, являются нарушения обоняния (гипосмия/аносмия) и вкуса (дисгевзия/ агевзия), в редких казуистических случаях, аналогично нейроинвазивному и нейротропному действию других вирусных агентов (вирус герпеса, гриппа, парамиксовирус Pneumophila parotiditis и пр.), возможно развитие острой сенсоневральной тугоухости [1, 3, 9, 12-23].

\section{Цель исследования}

Провести обзор литературных данных и представить к рассмотрению клинические наблюдения для оценки влияния вируса SARS-CoV-2 на слуховой анализатор пациентов с бессимптомной или легкой формой течения COVID-19.

Клинический случай № 1. На консультативный прием в СПб НИИ ЛОР обратилась женщина, 57 лет, с жалобами на снижение слуха на левое ухо и сопутствующий тиннитус в пораженном ухе.

Снижение слуха возникло остро и сопровождалось потерей обоняния и повышением температуры тела. Кроме однократного повышения температуры до $38,5{ }^{\circ} \mathrm{C}$, аносмии (на момент обращения обоняние полностью восстановилось) и отологических симптомов, жалоб со стороны других органов и систем не отмечалось.

Клинический случай № 2. Женщина, 42 лет, обратилась за консультативной помощью с жало- 
Acoumetry

\begin{tabular}{|c|c|c|c|c|c|c|c|c|}
\hline \multicolumn{3}{|c|}{ Пациент 1} & \multicolumn{3}{|c|}{ Пациент 2} & \multicolumn{3}{|c|}{ Пациент 3} \\
\hline $\mathrm{AD}$ & & AS & $\mathrm{AD}$ & & AS & $\mathrm{AD}$ & & AS \\
\hline- & СШ & + & - & СШ & + & - & СШ & + \\
\hline 6 & ШР & 0 & 6 & ШР & 0 & 6 & ШР & 0 \\
\hline$>6$ & PP & Кр. у рак. & $>6$ & $\mathrm{PP}$ & 6 & $>6$ & $\mathrm{PP}$ & 2,5 \\
\hline$\leftarrow$ & W & - & $\leftarrow$ & W & - & $\leftarrow$ & W & - \\
\hline+ & $\mathrm{R}$ & - & + & $\mathrm{R}$ & + & + & $\mathrm{R}$ & + \\
\hline+ & $\mathrm{F}$ & - & + & F & + & + & $\mathrm{F}$ & + \\
\hline
\end{tabular}

бами на снижение слуха на левое ухо и сопутствующий монолатеральный тиннитус.

Жалобы появились внезапно на фоне субфебрильной температуры, слабости, потери обоняния и вкуса.

Клинический случай № 3. Мужчина, 40 лет, при обращении предъявлял жалобы на снижение слуха и интенсивный шум в левом ухе.

В первый день у пациента повысилась температура тела до $37,4^{\circ} \mathrm{C}$, на следующий день появились жалобы на потерю обоняния с сохранением субфебрильной температуры, на третий день внезапно ухудшился слух и появился шум в левом ухе на фоне подъема температуры до $38,6^{\circ} \mathrm{C}$.

Из анамнеза известно, что пациенты снижение слуха ранее не отмечали, травмы, прием ототоксических препаратов и работу в условиях производственного шума отрицали. Наследственный анамнез не отягощен. У пациентки № 1 имелись сопутствующие хронические заболевания (гипертоническая болезнь, аутоиммунный тиреоидит), скорректированные приемом гипотензивных и гормональных препаратов, в остальных случаях сопутствующей соматической патологии выявлено не было. Диагноз COVID-19 был подтвержден определением PHK SARS-CoV-2 методом ПЦР (мазок из носоглотки).

При стандартном оториноларингологическом осмотре патологических изменений не обнаружено. Согласно тональной пороговой аудиометрии у всех пациентов было выявлено левостороннее повышение порогов слухового восприятия по сенсоневральному типу, что также подтверждалось данными акуметрии (табл., рис. 1). При акустической импедансометрии во всех случаях была зарегистрирована тимпанометрическая кривая типа А с повышением порогов стапедиального рефлекса на стороне поражения (рис. 2). Задержанная вызванная отоакустическая эмиссии (ЗВОАЭ) не регистрировалась на стороне локализации патологического процесса (рис. 3).

Всем пациентам был проведен курс противоневритической терапии с инфузионным введением системных глюкокортикостероидов [Sol.

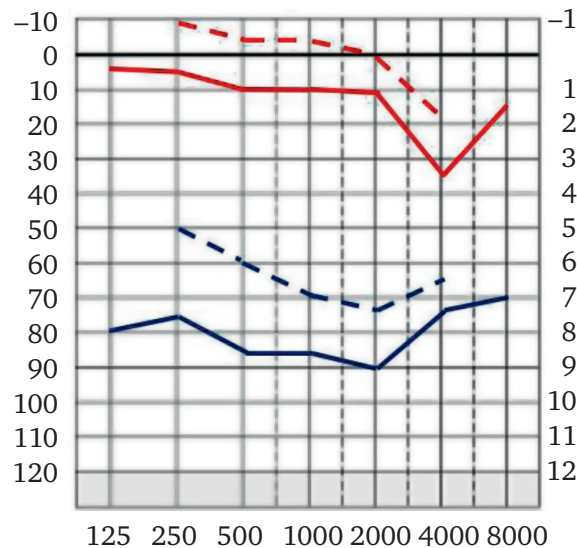

Рис. 1. Результаты тональной пороговой аудиометрии

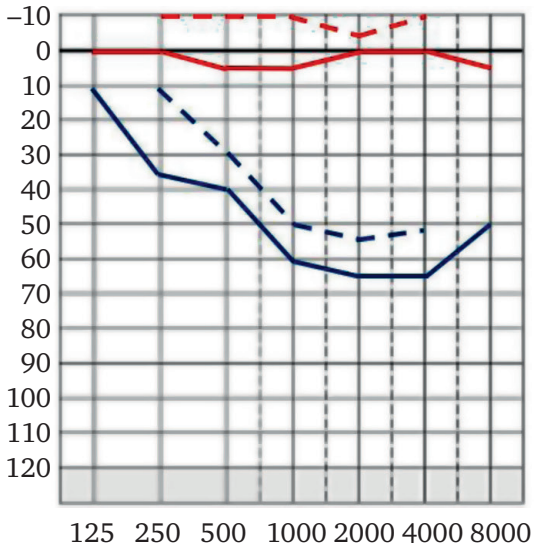

1252505001000200040008000

Fig 1. Pure tone audiometry results 


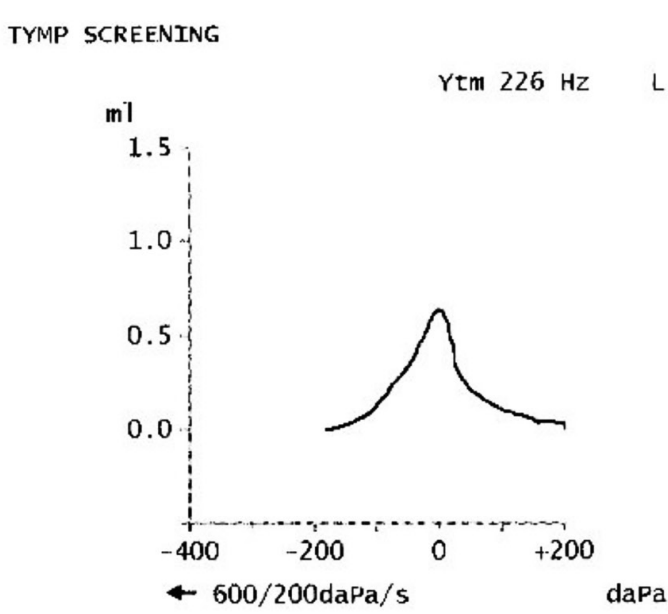

Рис. 2. Тимпанометрическая кривая типа A Fig 2. Type A tympanogram

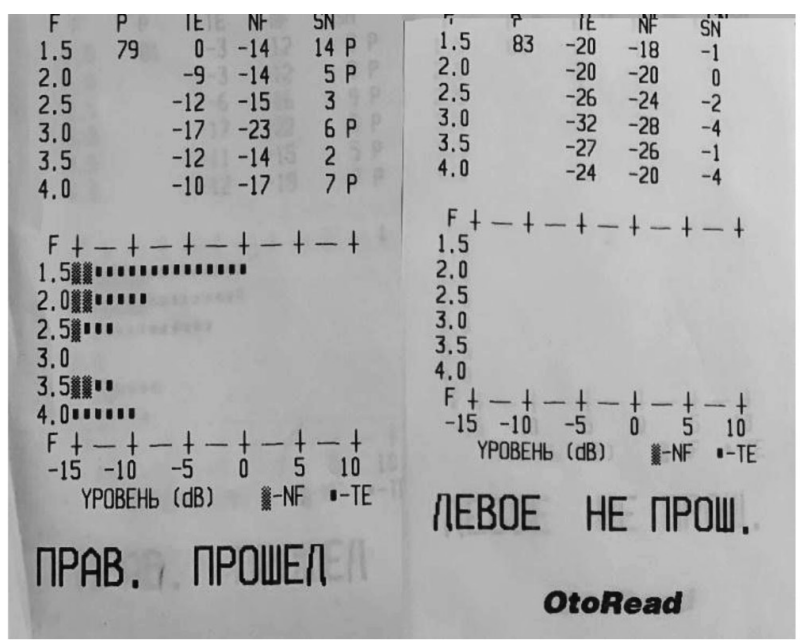

Рис. 3. Регистрация отоакустической эмиссии Fig. 3. Otoacoustic emission testing
Dexametasoni (по стандартной схеме лечения острой сенсоневральной тугоухости, метаболитов, антиоксидантов и вазоактивных препаратов. В результате проведенного лечения)], у пациентки № 1 состояние слуха не изменилось, что было обусловлено поздним обращением за специализированной помощью, в результате чего наступили необратимые изменения в структурах слухового анализатора. У пациентов № 2 и № 3 удалось достичь понижения порогов слухового восприятия, в среднем на 15-20 дБ, преимущественно на низких и средних частотах (250,500 и 1000 Гц). Частичное восстановление слуха при внезапной сенсоневральной тугоухости, обусловленной воздействием вируса SARS-CoV-2, подтверждается другими клиническими наблюдениями и, вероятно, может быть связано с особенностями патогенетических механизмов развития заболевания $[17,22]$.

\section{Обсуждение}

Большинство вирусов способны проникать через гематоэнцефалический барьер, что может проявляться различной неврологической симптоматикой, однако нейротропность и нейроинвазивность зависит от особенностей вирусного агента (мутации в определенных генах вирулентности) и состояния здоровья пациента (возраст, иммунный статус, наличие сопутствующих заболеваний) [24]. Некоторые вирусы (вирус гриппа, краснухи, цитомегаловирус, вирус Западного Нила и пр.) могут оказывать негативное воздействие на слуховой анализатор с развитием врожденной, а также внезапной приобретенной сенсоневральной тугоухости различной степени выраженности и локализации $[15,19,20,22,23$, $25,26]$.

Внезапная сенсоневральная тугоухость характеризуется повышением порогов слуха по типу звуковосприятия $\geq 30$ дБ на трех последовательных частотах в течение 72 часов. Ежегодно частота встречаемости заболевания в среднем составляет от 5 до 27 случаев на 100000 населения [21, 22]. Внезапное снижение слуха в $90 \%$ носит идиопатический характер, однако может быть сосудистой, аутоиммунной, а также вирусной этиологии. При воздействии инфекционного агента в большинстве случаев возникает острая потеря слуха с поражением системы звуковосприятия [12].

Все чаще появляются отдельные публикации, делающие акцент на том, что снижение слуха может являться одним из симптомов новой коронавирусной инфекции $[19,21,22]$, и согласно данному утверждению был выдвинут ряд гипотез, касающихся вероятных патогенетических механизмов развития сенсоневральной тугоухости при воздействии SARS-CoV-2 на центральную нервную систему (ЦНС) [19].

ЦНС обладает многоступенчатой системой защиты от вирусной инвазии, однако в некоторых случаях инфекционные агенты, в том числе и SARS-CoV-2, могут преодолевать гематоэнцефалический барьер и проникать в головной мозг гематогенным или ретроградным транссинаптическим путями. Неврологические осложнения при COVID-19 могут развиваться не только ввиду непосредственного проникновения инфекции в центральную нервную систему, а также за счет формирования выраженного мультисистемного воспалительного синдрома $[27,28]$.

Основной точкой воздействия вируса SARS$\mathrm{CoV}-2$ на клетку являются рецепторы ангиотензин-превращающего фермента 2 (АПФ2), которые содержатся в различных тканях организма, однако в большей степени в органах дыхательной, пищеварительной и нервной систем. В связи с особенностями патогенеза COVID-19 характе- 
ризуется полиорганными нарушениями и вариабельной клинической картиной, в том числе с поражением периферического и центрального отделов нервной системы, а также центра слуха, расположенного в височной доле головного мозга и содержащего рецепторы АПФ2. SARS-CoV-2 может не только непосредственно присоединяться к рецепторам АПФ2 в корковых центрах слухового анализатора, а также проникать внутрь эритроцитов и вытеснять из них кислород, что может служить фактором длительного повреждающего эффекта на структуры слуховой коры за счет развития оксидантного стресса $[10,21]$.

Известно, что одними из основных симптомов новой коронавирусной инфекции являются нарушения обоняния (что наблюдалось во всех представленных нами клинических случаях) и вкуса. SARS-CoV-2 может поражать рецепторы нейронов обонятельного эпителия, а также нейронов VII, IX или $\mathrm{X}$ черепных нервов, посредством которых инфекционный агент COVID-19 через обонятельный и солитарный (одиночный) тракты способен проникнуть в центральную нервную систему и, следовательно, оказывать влияние непосредственно на центральные отделы органа слуха. Вирус, обладая нейроинвазивностью, также может поражать слуховой нерв и мягкие ткани улитки с развитием кохлеоневрита, таким образом оказывая воздействие не только на центральный, но и на периферический отделы [21, 29].

При новой коронавирусной инфекции наблюдаются нарушения гемостаза, которые играют важную роль в патогенезе и клинических проявлениях заболевания. Коронавирус-индуцированная коагулопатия (КИК) ассоциирована с воспалительным повреждением эндотелиальных клеток, обильно экспрессирующих АПФ2, что приводит к развитию гиперкоагуляции и тромбозам. По результатам многочисленных исследований у пациентов с COVID-19 наблюдаются венозные, артериальные и микрососудистые тромбозы, следовательно, причиной развития острой сенсоневральной тугоухости в данном случае может рассматриваться ишемия зоны слуховой коры за счет окклюзии питающих сосудов [10, 29, 30].

На основании представленных данных о патогенетических механизмах действия SARS-CoV-2 становится очевидным, что развитие внезапной сенсоневральной тугоухости имеет полиморфологический и полиэтиологический характер, однако при тяжелых формах течения заболевания снижение слуха также может быть обусловлено преимущественно использованием ототоксических препаратов [10, 20].

Несмотря на достаточно обширный пул исследований, посвященных новой коронавирусной инфекции, на данный момент отмечается дефицит информации в отношении патологии органа слуха, ассоциированной с COVID-19. Представленные печатные работы вызывают ряд вопросов либо к дизайну исследования, либо в связи с недостаточной информативностью публикаций и в основном описывают единичные клинические наблюдения. Следовательно, несмотря на явную взаимосвязь SARS-CoV-2 с нарушениями слуха, требуется более детальное изучение данного вопроса в целях формирования окончательных выводов о патогенетических механизмах, лежащих в основе развития отологических осложнений, и уровнях поражения слухового анализатора в целях дальнейшей разработки эффективных схем специфической противоневритической терапии $[15,17,20,23]$.

\section{Заключение}

В связи с особенностями действия вируса SARS-CoV-2 новая короновирусная инфекция может сопровождаться полиорганными и полиморфологическими нарушениями, проявляющимися различной клинической картиной, в том числе с поражением центральной нервной системы и органа слуха. Неврологические и отологические осложнения могут быть обусловлены непосредственным проникновением инфекции в центральную нервную систему гематогенным или ретроградным транссинаптическим путями, а также формированием выраженного мультисистемного воспалительного синдрома. На данный момент одним из признаков бессимптомного или легкого течения COVID-19 может рассматриваться внезапная сенсоневральная тугоухость, что наглядно демонстрируют представленные клинические наблюдения. Несмотря на очевидную связь между нарушениями слуха и заболеванием, вызванным вирусом SARS-CoV-2, необходимо детальное изучение патогенетических механизмов развития сенсоневральной тугоухости, ассоциированной с COVID-19, для дальнейшей разработки эффективных схем лечения.

Авторы заявляют об отсутствии конфликта интересов.

\section{ЛИТЕРАTУРА/REFERENCES}

1. Временные методические рекомендации. Профилактика, диагностика и лечение новой короновирусной инфекции (COVID-19). Версия 11 (07.05.2021) [Vremennye metodicheskie rekomendatsii. Profilaktika, diagnostika $i$ lechenie novoi koronovirusnoi infektsii (COVID-19). Versiya 11 (In Russ.)] https://xn--80aesfpebagmfblc0a.xn--p1ai/ ai/doc/872/attach/Bmr_COVID-19_compressed.pdf 
2. Wiersinga W. J., Rhodes A., Cheng A. C., Peacock S. J., Prescott H. C. Pathophysiology, Transmission, Diagnosis, and Treatment of Coronavirus Disease 2019 (COVID-19). A Review. JAMA. 2020;25;324(8):782-793. https://doi. org/10.1001/jama.2020.12839

3. Krajewska J., Krajewski W., Zub K., Zatoński T. COVID-19 in otolaryngologist practice: a review of current knowledge. Eur. Arch. Otorhinolaryngol. 2020;277(7):1885-1897. https://doi.org/10.1007/s00405-020-05968-y

4. $\quad$ Li C., Zhao C., Bao J., Tang B., Wang Y., Gu B. Laboratory diagnosis of coronavirus disease-2019 (COVID-19). Clin. Chim. Acta. 2020;510:35-46. https://doi.org/10.1016/j.cca.2020.06.045

5. Vallamkondu J., John A., Wani W.Y., Ramadevi S. P., Jella K. K., Reddy P.H., Kandimalla R. SARS-CoV-2 pathophysiology and assessment of coronaviruses in CNS diseases with a focus on therapeutic targets. Biochim. Biophys. Acta Mol. Basis Dis. 2020;1;1866(10):165889. https://doi.org/10.1016/j.bbadis.2020.165889

6. Dhama K., Khan S., Tiwari R., Sircar S., Bhat S., Malik Y.S., Singh K.P., Chaicumpa W., Bonilla-Aldana D.K., RodriguezMorales A.J. Coronavirus Disease 2019-COVID-19. Clin. Microbiol. Rev. 2020;24;33(4):e00028-20. https://doi. org/10.1128/CMR.00028-20

7. Tizaoui K., Zidi I., Lee K. H., Ghayda R. A., Hong S. H., Li H., Smith L., Koyanagi A., Jacob L., Kronbichler A., Shin J. I. Update of the current knowledge on genetics, evolution, immunopathogenesis, and transmission for coronavirus disease 19 (COVID-19). Int. J. Biol. Sci. 2020;12;16(15):2906-2923. https://doi.org/10.7150/ijbs.48812

8. COVID-19 Dashboard by the Center for Systems Science and Engineering (CSSE) at Johns Hopkins University (JHU) https://coronavirus.jhu.edu/map.html

9. Lai C. C., Ko W. C., Lee P. I., Jean S. S., Hsueh P. R. Extra-respiratory manifestations of COVID-19. Int. J. Antimicrob. Agents. 2020;56(2):106024. DOI 10.1016/j.jjantimicag.2020.106024

10. Дайхес Н. А., Карнеева О. В., Мачалов А. С., Кузнецов А. О., Сапожников Я. М., Балакина А. В., Хулугурова Л. Н., Карпов В. Л. Аудиологический профиль пациентов при заболевании, вызванном вирусом SARS-CoV-2. Вестник оториноларингологии. 2020;85(5):6-11 [Daikhes N. A., Karneeva O. V., Machalov A. S., Kuznetcov A. O., Sapozhnikov Ya. M., Balakina A. V., Khulugurova L. N., Karpov V. L. Audiological profile of patients with SARSCo-V-2 PCR-positive cases. Vestnik otorinolaringologii. 2020;85(5):6-11. (In Russ.)]. https://doi.org/10.17116/ otorino2020850516

11. Abu-Rumeileh S., Abdelhak A., Foschi M., Tumani H., Otto M. Guillain-Barré syndrome spectrum associated with COVID-19: an up-to-date systematic review of 73 cases. J Neurol. 2020;25:1-38. https://doi.org/10.1007/s00415020-10124-x

12. Freni F., Meduri A., Gazia F., Nicastro V., Galletti C., Aragona P., Galletti C., Galletti B., Galletti F. Symptomatology in head and neck district in coronavirus disease (COVID-19): A possible neuroinvasive action of SARS-CoV-2. Am. J. Otolaryngol. 2020;41(5):102612. https://doi.org/10.1016/j.amjoto.2020.102612

13. Esakandari H., Nabi-Afjadi M., Fakkari-Afjadi J., Farahmandian N., Miresmaeili S.M., Bahreini E. A comprehensive review of COVID-19 characteristics. Biol. Proced. Online. 2020;4;22:19. https://doi.org/10.1186/s12575-02000128-2

14. Elibol E. Otolaryngological symptoms in COVID-19. Eur. Arch. Otorhinolaryngol. 2021;278(4):1233-1236. https:// doi.org/10.1007/s00405-020-06319-7

15. Mustafa M. W. M. Audiological profile of asymptomatic Covid-19 PCR-positive cases. Am. J. Otolaryngol. 2020;41(3):102483. https://doi.org/10.1016/j.amjoto.2020.102483

16. El-Anwar M. W., Elzayat S., Fouad Y. A. ENT manifestation in COVID-19 patients. Auris Nasus Larynx. 2020;47(4):559564. https://doi.org/10.1016/j.anl.2020.06.003

17. Koumpa F. S., Forde C. T., Manjaly J. G. Sudden irreversible hearing loss post COVID-19. BMJ Case Rep. 2020;13;13(11):e238419. https://doi.org/10.1136/bcr-2020-238419

18. Özçelik Korkmaz M., Eğilmez O. K., Özçelik M. A., Güven M. Otolaryngological manifestations of hospitalised patients with confirmed COVID-19 infection. Eur. Arch Otorhinolaryngol. 2020;3:1-11. https://doi.org/10.1007/s00405020-06396-8

19. Saniasiaya J. Hearing Loss in SARS-CoV-2: What Do We Know? Ear Nose Throat J. 2021;100(2_suppl):152S-154S. https://doi.org/10.1177/0145561320946902

20. Almufarrij I., Uus K., Munro K.J. Does coronavirus affect the audio-vestibular system? A rapid systematic review. Int. J. Audiol. 2020;59(7):487-491. https://doi.org/10.1080/14992027.2020.1776406

21. Harenberg J., Jonas J. B., Trecca E. M. C. A Liaison between Sudden Sensorineural Hearing Loss and SARS-CoV-2 Infection. Thromb. Haemost. 2020;120(9):1237-1239. https://doi.org/10.1055/s-0040-1714370

22. Lang B., Hintze J., Conlon B. Coronavirus disease 2019 and sudden sensorineural hearing loss. J. Laryngol. Otol. 2020;1:1-3. https://doi.org/10.1017/S0022215120002145

23. Karimi-Galougahi M., Naeini A. S., Raad N., Mikaniki N., Ghorbani J. Vertigo and hearing loss during the COVID-19 pandemic-is there an association? Acta Otorhinolaryngol.Ital. 2020;40(6):463-465. https://doi.org/10.14639/0392100X-N0820

24. Yachou Y., El Idrissi A., Belapasov V., Ait Benali S. Neuroinvasion, neurotropic, and neuroinflammatory events of SARS-CoV-2: understanding the neurological manifestations in COVID-19 patients. Neurol. Sci. 2020;41(10):26572669. https://doi.org/10.1007/s10072-020-04575-3

25. Cohen B. E., Durstenfeld A., Roehm P. C. Viral causes of hearing loss: a review for hearing health professionals. Trends Hear. 2014;29;18:2331216514541361. https://doi.org/10.1177/2331216514541361

26. Chirakkal P., Al Hail A. N., Zada N., Vijayakumar D. S. COVID-19 and Tinnitus. Ear Nose Throat J. 2021;100(2_ suppl):160S-162S. https://doi.org/10.1177/0145561320974849 
27. Montalvan V., Lee J., Bueso T., De Toledo J., Rivas K. Neurological manifestations of COVID-19 and other coronavirus infections: A systematic review. Clin. Neurol. Neurosurg. 2020;194:105921. https://doi.org/10.1016/j. clineuro.2020.105921

28. Li Z., Liu T., Yang N., Han D., Mi X., Li Y., Liu K., Vuylsteke A., Xiang H., Guo X. Neurological manifestations of patients with COVID-19: potential routes of SARS-CoV-2 neuroinvasion from the periphery to the brain. Front Med. 2020;14(5):533-541. https://doi.org/10.1007/s11684-020-0786-5

29. Галстян Г. М. Коагулопатия при COVID-19. Пульмонология. 2020;30(5):645-657 [Galstyan G.M. Coagulopathy in COVID-19. Pul'monologiya. 2020;30(5): 645-657. (In Russ.)]. https://doi.org/10.18093/0869-0189-2020-30-5645-657

30. Sparks M. A., South A. M., Badley A. D., Baker-Smith C. M., Batlle D., Bozkurt B., Cattaneo R., Crowley S. D., Dell'Italia L. J., Ford A. L., Griendling K., Gurley S. B., Kasner S. E., Murray J. A., Nath K. A., Pfeffer M. A., Rangaswami J., Taylor W. R., Garovic V. D. Severe Acute Respiratory Syndrome Coronavirus 2, COVID-19, and the ReninAngiotensin System: Pressing Needs and Best Research Practices. Hypertension. 2020;76(5):1350-1367. https://doi. org/10.1161/HYPERTENSIONAHA.120.15948

Информация об авторах

Астащенко Светлана Витальевна - доктор медицинских наук, заведующая хирургическим отделением для взрослых, Санкт-Петербургский научно-исследовательский институт уха, горла, носа и речи (190013, Россия, Санкт-Петербург, Бронницкая ул., д. 9); e-mail: docte@yandex.ru

ORCID: https://orcid.org/0000-0003-1863-2279

Мегрелишвили Спартак Михайлович - заведующий сурдологическим отделением, Санкт-Петербургский научно-исследовательский институт уха, горла, носа и речи (190013, Россия, Санкт-Петербург, Бронницкая ул., д. 9); e-mail: 3162883@mail.ru

$\triangle$ Щербакова Яна Леонидовна - кандидат медицинских наук, научный сотрудник отдела диагностики и реабилитации нарушений слуха, Санкт-Петербургский научно-исследовательский институт уха, горла, носа и речи (190013, Россия, СанктПетербург, Бронницкая ул., д. 9); e-mail: shcherbakova_ya@mail.ru ORCID: https://orcid.org/0000-0002-1203-3120

Information about authors

Svetlana V. Astashchenko - MD, Head of Adult Surgery Department, Saint Petersburg Research Institute of Ear, Throat, Nose and Speech (9, Bronnitskaya Str., Saint Petersburg, Russia, 190013); e-mail: docte@yandex.ru

ORCID: https://orcid.org/0000-0003-1863-2279

Spartak M. Megrelishvili - Head of Audiology Department, Saint Petersburg Research Institute of Ear, Throat, Nose and Speech (9, Bronnitskaya Str., Saint Petersburg, Russia, 190013); e-mail: 3162883@mail.ru

$\triangle$ Yana L. Shcherbakova - MD Candidate, Researcher of Department of Diagnosis and Rehabilitation of Hearing Disorders, Saint Petersburg Research Institute of Ear, Throat, Nose and Speech (9, Bronnitskaya Str., Saint Petersburg, Russia, 190013); e-mail: shcherbakova_ya@mail.ru

ORCID: https://orcid.org/0000-0002-1203-3120 